\title{
EFEITOS DA VERBALIZAÇÃO DO PENSAMENTO EM VOZ ALTA SOBRE A VELOCIDADE, A REVISÃO E A SEGMENTAÇÃO NA TRADUÇÃO' ${ }^{1}$
}

\section{EFFECTS OF THINK ALOUD ON TRANSLATION SPEED, REVISION, AND SEGMENTATION}

\author{
Arnt Lykke JAKOBSEN ${ }^{2}$ \\ Tradução de: Isabelle Fernandes de OLIVEIRA ${ }^{3}$
}

\begin{abstract}
Resumo: Quatro estudantes de mestrado em tradução e cinco tradutores expertos traduziram dois textos do dinamarquês para o inglês e dois textos do inglês para o dinamarquês. Em cada uma das direções, uma tarefa de tradução foi realizada concomitantemente à verbalização do pensamento em voz alta (do inglês, think aloud protocol, ou TAP) e a outra foi executada sem essa verbalização. As traduções foram realizadas no computador, e todos os acionamentos de teclas e mouse foram registrados utilizando-se o software Translog. O objetivo foi determinar que tipo de influência, existindo alguma, a verbalização do pensamento em voz alta poderia exercer sobre a velocidade da tradução, sobre a quantidade de texto revisado e sobre a segmentação determinada por pausas. Esperava-se que a verbalização do pensamento em voz alta tornasse o processo de tradução mais lento, mas que não afetasse a revisão ou a segmentação. Constataram-se, em ambos os grupos, efeitos significativos sobre a velocidade, com retardo do processo tradutório em aproximadamente $25 \%$. Não se encontrou efeito significativo sobre a revisão. Entretanto, contrariando as expectativas, observaramse efeitos significativos sobre a segmentação: a verbalização concomitante do pensamento em voz alta forçou os dois grupos de tradutores a processarem os textos em segmentos menores.
\end{abstract}

Palavras-chave: Verbalização do pensamento em voz alta. Velocidade de tradução. Revisão na tradução. Segmentação na tradução.

\section{Introdução}

O principal método utilizado na investigação do processamento cognitivo das informações em uma tarefa de tradução tem sido o método introspectivo de protocolo de verbalização do pensamento em voz alta (do inglês, think aloud protocol, ou TAP), descrito por Ericsson e Simon (1984). Contudo, existe outro método, mais mecânico, para a investigação, mapeamento ou exame do processo tradutório (cf. HANSEN, 1999; JÄÄSKELÄINEN, 1999; TIRKKONEN-CONDIT; JÄÄSKELÄINEN, 2000). O registro em

\footnotetext{
${ }^{1}$ Agradecemos ao autor e à editora John Benjamins Publishing Company a gentileza de cederem os direitos para a publicação desta versão traduzida. Referência do artigo original: JAKOBSEN, Arnt Lykke. Effects of think aloud on translation speed, revision, and segmentation. In: ALVES, Alves (Ed.). Triangulating translation: perspectives in process oriented research. Amsterdã/Filadélfia: John Benjamins, 2003. p. 69-95. O volume onde o texto original foi publicado se encontra à venda no site da editora John Benjamins: https://benjamins.com/\#catalog/books/btl.45/main. Acesso em 13 de dezembro de 2017.

${ }^{2}$ Copenhaghen Business School

${ }^{3}$ Tradutora do inglês. Possui Bacharelado em Tradução pela Universidade Federal da Paraíba (2017). E-mail: bellebelly2@gmail.com. Tradução supervisionada pela Prof ${ }^{a} \operatorname{Dr}^{a}$ Tânia Liparini Campos.
} 
tempo real dos acionamentos de teclas e mouse fornece um método complementar para a investigação do processo a partir do comportamento do tradutor diante do teclado e do mouse (JAKOBSEN,1998, 19994; JAKOBSEN; SCHOU, 1999).

Com o advento e a popularização dos computadores pessoais, a maioria das traduções vem sendo digitada utilizando-se o teclado, o que resulta em um aprimoramento das habilidades de digitação dos tradutores a um nível (em alguns casos, pelo menos) em que a digitação é praticamente tão imediata e automática quanto à fala. Em todo caso, editar um texto tornou-se tão fácil que a maioria dos tradutores prefere agora teclar suas ideias imediatamente em vez de finalizar o processamento de uma oração ou sentença completa antes de iniciar a digitação. Um efeito disso é que, quando registrados, os acionamentos de teclas efetuados por um tradutor constituem o que se pode chamar de "protocolo de digitação em tempo real" ou "protocolo digitado de verbalização do pensamento em tempo real", que contém informações sobre os primeiros impulsos, falsos inícios, revisões etc., de forma muito parecida com aquela que se obtém utilizando-se os protocolos de verbalização do pensamento em voz alta.

O registro de acionamentos de teclas e mouse não substitui as informações que podem ser obtidas por meio de TAP; contudo, a combinação de ambos os métodos consiste em uma forma robusta de triangular observações e aventar hipóteses sobre a tradução (ALVES, 2001). Se uma fonte de dados se exaure em determinado ponto, é possível contar com os dados da outra, de modo que um método complementará o outro. Se as análises dos dados de duas fontes forem convergentes, qualquer resultado encontrado será mais robusto que aquele baseado apenas em uma fonte de dados.

Dispondo-se de dois métodos, um pode ser utilizado para validar (ou invalidar) o outro, sendo esse o objetivo do presente trabalho. Propõe-se aqui indagar um dos pressupostos centrais do uso de TAP, qual seja: a vocalização de informações oralmente codificadas não acarreta sobrecarga adicional quanto ao tempo ou à capacidade de processamento. De acordo com Ericsson e Simon (1993, p. 62),

... o pressuposto básico é que, quando o processador central serve ou ativa uma estrutura na memória que é apenas codificada oralmente, essa estrutura pode, então, ao mesmo tempo ser vocalizada abertamente sem fazer exigências adicionais em termos de tempo ou de capacidade de processamento. Quando os conteúdos da memória de curto prazo são palavras (i.e., são codificados oralmente), podemos, a qualquer momento, dizer essas palavras sem interferência do processo em andamento.

\footnotetext{
${ }^{4}$ Jakobsen (1999) encontra-se traduzido neste volume.
} 
As estruturas da memória ativadas durante o ato tradutório são oralmente codificadas no mesmo sentido utilizado por Ericsson e Simon (1993). O pressuposto básico desses autores parece, portanto, ser aplicável, sem restrições, à tradução.

Parte do fascínio desse pressuposto é que, para muitas pessoas, ele é um contrassenso. Intuitivamente, somos tentados a achar que o TAP contribui para a sobrecarga cognitiva a que está submetido o tradutor e que o processo de tradução deve, por conseguinte, ser de alguma forma afetado (negativamente) por essa técnica. A princípio, parece pouco provável que exista a possibilidade de verbalização (i.e., abrir um canal de articulação adicional e concomitante), sem que haja atraso, ou qualquer outro efeito, sobre o processo cognitivo principal, qual seja, o processo de tradução.

Ericsson e Simon (1993, p. 77) reconhecem que, em alguns casos, o TAP pode retardar o processo cognitivo principal:

Nosso modelo [...] prevê que a produção de expressões verbais de acordo com as instruções para a verbalização do pensamento em voz alta não afetará a velocidade do desempenho a menos que as verbalizações precisem ser sequenciadas.

Não se prevê qualquer outro efeito causado pelo TAP em voz alta sobre o processo cognitivo principal.

Para testar a afirmação de Ericsson e Simon (1993), decidiu-se avaliar o efeito do TAP primeiramente sobre a velocidade da tradução. No entanto, como a diminuição no ritmo talvez pudesse ser atribuída à necessidade de sequenciamento das verbalizações em uma fila de espera, decidiu-se também investigar possíveis efeitos causados na forma como as tarefas tradutórias são executadas (por meio da análise da quantidade de revisões feitas) e na capacidade de processamento (por meio da contagem do número de segmentos de produção textual por unidade do texto-fonte). Se nenhum efeito, positivo ou negativo, for encontrado, a hipótese de Ericsson e Simon (1993) será corroborada. Se forem encontrados quaisquer efeitos, eles não invalidarão o método de verbalização, mas indicarão a relevância de se determinar o impacto desses efeitos sobre a tradução, em que áreas eles operam e em que medida podemos dizer que afetam o processo tradutório, negativa ou positivamente. 


\section{Desenho Experimental}

Nove participantes, sendo quatro tradutores semiprofissionais (estudantes de mestrado em tradução no último período acadêmico) e cinco tradutores expertos com no mínimo dois anos de experiência profissional, traduziram, cada um, quatro textos curtos.

Os participantes realizaram um rápido aquecimento antes da sessão de tradução. Esse aquecimento teve como objetivo familiarizar os participantes com o software Translog e com o experimento em geral. Incluiu-se, nessa etapa, uma breve instrução sobre o TAP e uma oportunidade de praticar a verbalização do pensamento em voz alta durante o ato tradutório.

Após as instruções e o exercício de aquecimento antes da atividade tradutória, solicitou-se aos participantes que traduzissem quatro textos (em ordem aleatória) do dinamarquês para o inglês e do inglês para o dinamarquês. Os dois textos-fonte na língua dinamarquesa (textos 1 e 2 nas tabelas) tinham 367 e 522 caracteres, respectivamente (incluindo espaços). Os dois textos-fonte em língua inglesa (textos 3 e 4 nas tabelas) tinham uma maior quantidade de caracteres (760 e 1001, respectivamente), pois se esperava que a tradução para a L1 (dinamarquês) seria consideravelmente mais rápida do que a tradução para a L2 (inglês). Todos os textos apareciam por completo no software Translog.

Solicitou-se aos participantes que trabalhassem em seus ritmos usuais. Foram também informados de que o experimento provavelmente duraria entre uma e duas horas, mas não havia limite de tempo. De fato, as sessões experimentais duraram, no geral, entre 1 e 2 horas para as quatro tarefas de tradução.

Os participantes tiveram acesso a dicionários bilíngues diversos e à internet. A tradução da L1 para a L2 foi inclusa no experimento porque que seria interessante investigar se a verbalização (que presumivelmente seria realizada predominantemente na L1) afetaria a produção do texto-alvo na L2 de forma diferente do que ocorreria na produção do texto-alvo na L1.

Em cada uma das direções, uma tarefa de tradução foi realizada com o TAP e a outra, sem. Os TAP foram gravados em fitas de áudio; e todos os acionamentos de teclas e mouse (com exceção daqueles para operações fora do Translog, como durante a navegação na internet) foram registrados no Translog juntamente com suas respectivas informações de tempo.

Todos os tradutores declararam que o dinamarquês era a língua mais predominante (L1). Todavia, o fato de o inglês ser a língua materna de um dos tradutores profissionais ficou 
evidente nos dados (e causou uma ligeira indistinção em alguns aspectos gerais dos resultados).

Como a análise inicial (relatada no presente trabalho) baseou-se apenas em dados quantitativos, as informações contidas nas gravações de áudio não foram utilizadas no presente trabalho. Ademais, as análises quantitativas basearam-se nos números de toda a tarefa de tradução (e.g., as fases de orientação, redação e revisão não foram consideradas separadamente).

\section{Hipóteses}

Esperava-se, em relação à velocidade, que:

1. a tradução seria mais lenta com o TAP do que sem ele nos dois grupos, tanto para a tradução da L2 para a L1 como para a tradução da L1 para a L2;

2. os tradutores expertos completariam as tarefas com mais rapidez do que os estudantes de tradução, independentemente da direcionalidade e da condição de uso ou não do TAP;

3. a tradução da L1 para a L2 seria mais lenta do que a tradução da L2 para a L1 nos dois grupos de tradutores independentemente da realização ou não do TAP. Esperava-se que a tradução da L1 para a L2 fosse mais lenta, pois a verbalização na L1 inibiria a produção do texto-alvo na L2.

Esperava-se, em relação à revisão, que:

4. independentemente da realização ou não do TAP, haveria mais revisão na tradução da L1 para L2 do que na tradução da L2 para a L1, visto que os dois grupos de tradutores estariam empenhando maior esforço para encontrar os "equivalentes" apropriados quando estivessem traduzindo para a L2 do que na tradução para a L1;

5. a realização ou não do TAP, seguindo o que fora preconizado por Ericsson e Simon (1993), não teria qualquer efeito sobre a quantidade de texto revisado.

Esperava-se, em relação à segmentação, que:

6. os segmentos variariam de acordo com a direcionalidade de forma que haveria relativamente mais segmentos na tradução da L1 para a L2 do que na tradução da L2 para L1, na qual os participantes teriam maior sucesso em encontrar traduções idiomáticas no nível do sintagma e da oração. 
7. Seguindo o que fora postulado por Ericsson e Simon (1993), a realização do TAP não teria efeito sobre o número relativo de segmentos.

\section{Efeitos sobre a velocidade}

\subsection{Grupo de tradutores semiprofissionais}

Tabela 1 - Valores brutos da duração da atividade e dos acionamentos de teclas no grupo dos semiprofissionais (participantes 1-4)

\begin{tabular}{|c|c|c|c|c|c|c|c|c|}
\hline Part. & Texto & $\begin{array}{c}\text { Condição } \\
\text { (TAP) }\end{array}$ & Direção & $\begin{array}{c}\text { Duração } \\
\text { (min:s) }\end{array}$ & $\begin{array}{c}\text { Total de } \\
\text { teclas }\end{array}$ & $\begin{array}{c}\text { Teclas de } \\
\text { produção } \\
\text { textual }\end{array}$ & Teclas/min & $\begin{array}{c}\text { Teclas de } \\
\text { produção } \\
\text { textual/min }\end{array}$ \\
\hline 1 & 1 & Com TAP & $\mathrm{L} 1 \rightarrow \mathrm{L} 2$ & 19:51 & 560 & 461 & 28 & 23 \\
\hline 2 & 1 & Com TAP & $\mathrm{L} 1 \rightarrow \mathrm{L} 2$ & $17: 48$ & 863 & 631 & 48 & 35 \\
\hline 3 & 1 & Com TAP & $\mathrm{L} 1 \rightarrow \mathrm{L} 2$ & $13: 55$ & 1044 & 726 & 75 & 52 \\
\hline 4 & 1 & Com TAP & $\mathrm{L} 1 \rightarrow \mathrm{L} 2$ & $19: 23$ & 601 & 498 & 31 & 26 \\
\hline \multicolumn{4}{|c|}{ Média } & $17: 44$ & 767,0 & 579 & 45,5 & 34,0 \\
\hline
\end{tabular}

\begin{tabular}{|c|c|c|c|c|c|c|c|c|}
\hline 1 & 2 & Sem TAP & $\mathrm{L} 1 \rightarrow \mathrm{L} 2$ & $16: 47$ & 704 & 632 & 42 & 38 \\
\hline 2 & 2 & Sem TAP & $\mathrm{L} 1 \rightarrow \mathrm{L} 2$ & $12: 46$ & 937 & 693 & 73 & 54 \\
\hline 3 & 2 & Sem TAP & $\mathrm{L} 1 \rightarrow \mathrm{L} 2$ & $9: 36$ & 710 & 550 & 74 & 57 \\
\hline 4 & 2 & Sem TAP & $\mathrm{L} 1 \rightarrow \mathrm{L} 2$ & $25: 47$ & 1078 & 759 & 42 & 29 \\
\hline \multicolumn{4}{|c|}{ Média } & $16: 14$ & 8573 & 658,0 & 57,8 & 44,5 \\
\hline
\end{tabular}

\begin{tabular}{|c|c|c|c|c|c|c|c|c|}
\hline 1 & 3 & Sem TAP & $\mathrm{L} 2 \rightarrow \mathrm{L} 1$ & $24: 46$ & 1062 & 822 & 43 & 33 \\
\hline 2 & 3 & Sem TAP & $\mathrm{L} 2 \rightarrow \mathrm{L} 1$ & $15: 37$ & 1278 & 1053 & 82 & 67 \\
\hline 3 & 3 & Sem TAP & $\mathrm{L} 2 \rightarrow \mathrm{L} 1$ & $14: 32$ & 1214 & 916 & 84 & 63 \\
\hline 4 & 3 & Sem TAP & $\mathrm{L} 2 \rightarrow \mathrm{L} 1$ & $24: 29$ & 1556 & 1078 & 64 & 44 \\
\hline \multicolumn{4}{|c|}{ Média } & 19:51 & 1277,5 & 967,3 & 68,3 & 51,8 \\
\hline
\end{tabular}

\begin{tabular}{|c|c|c|c|c|c|c|c|c|}
\hline 1 & 4 & Com TAP & $\mathrm{L} 2 \rightarrow \mathrm{L} 1$ & $42: 57$ & 1311 & 1089 & 31 & 25 \\
\hline 2 & 4 & Com TAP & $\mathrm{L} 2 \rightarrow \mathrm{L} 1$ & $41: 45$ & 2209 & 1690 & 53 & 40 \\
\hline 3 & 4 & Com TAP & $\mathrm{L} 2 \rightarrow \mathrm{L} 1$ & $19: 20$ & 1524 & 1245 & 79 & 64 \\
\hline 4 & 4 & Com TAP & $\mathrm{L} 2 \rightarrow \mathrm{L} 1$ & $37: 31$ & 2175 & 1276 & 58 & 34 \\
\hline \multicolumn{4}{|c|}{ Média } & $35: 23$ & 1804,8 & 1325 & 55,3 & 40,8 \\
\hline
\end{tabular}

\footnotetext{
Nota: Part.=participante; TAP=protocolo de verbalização do pensamento em voz alta.
} 
Tabela 2 - Diferença média nas velocidades no grupo de semiprofissionais calculada por meio da média do número total de acionamentos de teclas por minuto e por meio do número de teclas de produção textual por minuto com e sem a realização do TAP

\begin{tabular}{c|c|c|c|c}
\hline Participante & $\begin{array}{c}\text { Teclas/min } \\
\text { com TAP }\end{array}$ & $\begin{array}{c}\text { Teclas/min } \\
\text { sem TAP }\end{array}$ & $\begin{array}{c}\text { Teclas de } \\
\text { produção/min com TAP }\end{array}$ & $\begin{array}{c}\text { Teclas de } \\
\text { produção/min sem TAP }\end{array}$ \\
\hline 1 & 29,5 & 42,5 & 24 & 35,5 \\
\hline 2 & 50,5 & 77,5 & 37,5 & 60,5 \\
\hline 3 & 77 & 79 & 58 & 60 \\
\hline 4 & 44,5 & 53 & 30 & 36,5 \\
\hline Média & 50,4 & 63 & 37,4 & 48,1 \\
\hline
\end{tabular}

Nota: $\mathrm{TAP}=$ protocolo de verbalização do pensamento em voz alta.

No grupo dos tradutores semiprofissionais, verificou-se, conforme mostra a Tabela 1, um efeito claro do TAP sobre a velocidade (interpretada tanto a partir do número total de acionamentos de teclas e mouse como a partir do número total de caracteres de produção textual digitados por unidade de tempo). O valor da variável "duração (min:s)" foi o tempo total, em minutos e segundos, que o participante despendeu para concluir a tarefa. $\mathrm{O}$ valor "teclas/min" foi o número total de acionamentos de teclas por minuto. O valor "teclas de produção textual/min" foi o número de caracteres de produção textual digitados por minuto (incluindo-se os espaços e as quebras de linha, mas excluindo-se as teclas de delete e backspace, os caracteres excluídos e os movimentos no cursor realizados através do teclado). Calculando-se, para os textos, a média dos valores por minuto da Tabela 1, encontraram-se os seguintes valores da Tabela 2 para a velocidade com e sem o TAP.

Para o grupo de tradutores semiprofissionais como um todo, a realização do TAP reduziu o número total de teclas por unidade de tempo em 20\% (de 63 para 50,4), bem como o número de teclas de produção textual por unidade de tempo em 22,3\% (de 48,1 para 37,4). Quando observados individualmente, os participantes mostraram uma variação considerável, de um mínimo de 24 a um máximo de 60,5 teclas de produção textual por minuto. Todos os participantes produziram menos texto por minuto com o TAP do que sem o protocolo, entretanto, os participantes foram aparentemente afetados de forma desigual pela realização do TAP. O participante 2 produziu 38\% a menos com o TAP, ao passo que o volume de produção textual por minuto do participante 3 praticamente não foi afetado pelo TAP. 


\subsection{Grupo dos tradutores expertos}

O grupo dos tradutores expertos realizou a atividade tradutória com os mesmos quatro textos utilizados pelo grupo dos semiprofissionais. A condição de realização ou não do TAP para a tradução de cada um dos textos foi oposta à do grupo dos semiprofissionais, ou seja, sem verbalização para os textos 1 e 4 e com verbalização para os textos 2 e 3 . A direcionalidade permaneceu a mesma: $\mathrm{L} 1 \rightarrow \mathrm{L} 2$ para os textos 1 e 2 ; e $\mathrm{L} 2 \rightarrow \mathrm{L} 1$ para os textos 3 e 4. Os valores obtidos neste grupo estão dispostos na Tabela 3.

Tabela 3 - Valores brutos da duração da atividade e dos acionamentos de teclas no grupo dos tradutores expertos (participantes 5-9)

\begin{tabular}{c|c|c|c|c|c|c|c}
\hline Part. & Texto & $\begin{array}{c}\text { Condição } \\
\text { (TAP) }\end{array}$ & $\begin{array}{c}\text { Duração } \\
\text { (min:s) }\end{array}$ & $\begin{array}{c}\text { Total de } \\
\text { teclas }\end{array}$ & $\begin{array}{c}\text { Teclas de } \\
\text { produção } \\
\text { textual }\end{array}$ & Teclas/min & $\begin{array}{c}\text { Teclas de } \\
\text { produção } \\
\text { textual/min }\end{array}$ \\
\hline 5 & 1 & Sem TAP & $10: 11$ & 638 & 510 & 63 & 50 \\
\hline 6 & 1 & Sem TAP & $6: 45$ & 754 & 527 & 112 & 78 \\
\hline 7 & 1 & Sem TAP & $15: 39$ & 1410 & 745 & 90 & 48 \\
\hline 8 & 1 & Sem TAP & $6: 56$ & 519 & 442 & 75 & 64 \\
\hline 9 & 1 & Sem TAP & $15: 47$ & 597 & 455 & 38 & 29 \\
\hline \multicolumn{2}{|c|}{ Média } & $11: 04$ & 783,6 & 535,8 & 75,6 & 53,8 \\
\hline
\end{tabular}

\begin{tabular}{|c|c|c|c|c|c|c|c|}
\hline 5 & 2 & Com TAP & $12: 05$ & 711 & 600 & 59 & 50 \\
\hline 6 & 2 & Com TAP & $16: 51$ & 1074 & 731 & 64 & 43 \\
\hline 7 & 2 & Com TAP & 29:31 & 1422 & 753 & 48 & 26 \\
\hline 8 & 2 & Com TAP & $13: 26$ & 852 & 678 & 63 & 50 \\
\hline 9 & 2 & Com TAP & $12: 58$ & 750 & 609 & 58 & 47 \\
\hline \multicolumn{3}{|c|}{ Média } & $16: 58$ & 961,8 & 674,2 & 58,4 & 43,2 \\
\hline
\end{tabular}

\begin{tabular}{|c|c|c|c|c|c|c|c|}
\hline 5 & 3 & Com TAP & $18: 21$ & 1120 & 967 & 61 & 53 \\
\hline 6 & 3 & Com TAP & $18: 59$ & 1524 & 981 & 80 & 52 \\
\hline 7 & 3 & Com TAP & $23: 32$ & 1972 & 1143 & 84 & 49 \\
\hline 8 & 3 & Com TAP & $17: 47$ & 1143 & 965 & 64 & 54 \\
\hline 9 & 3 & Com TAP & $27: 39$ & 1183 & 956 & 43 & 35 \\
\hline \multicolumn{3}{|c|}{ Média } & $21: 16$ & 1388,4 & 1002,4 & 66,4 & 48,6 \\
\hline
\end{tabular}

\begin{tabular}{|c|c|c|c|c|c|c|c|}
\hline 5 & 4 & Sem TAP & $22: 02$ & 1474 & 1277 & 67 & 58 \\
\hline 6 & 4 & Sem TAP & $15: 59$ & 1955 & 1368 & 122 & 86 \\
\hline 7 & 4 & Sem TAP & $26: 53$ & 3732 & 1788 & 139 & 66 \\
\hline 8 & 4 & Sem TAP & $19: 36$ & 1697 & 1396 & 87 & 71 \\
\hline 9 & 4 & Sem TAP & $28: 38$ & 2100 & 1434 & 73 & 50 \\
\hline \multicolumn{3}{|c|}{ Média } & $22: 38$ & 2191,6 & 1452,6 & 97,6 & 66,2 \\
\hline
\end{tabular}

Nota: Part.=participante; TAP=protocolo de verbalização do pensamento em voz alta. 
Tabela 4 - Diferença média nas velocidades no grupo de tradutores expertos calculada por meio da média do número total de acionamentos de teclas por minuto e por meio do número de teclas de produção textual por minuto com e sem a realização do TAP

\begin{tabular}{c|c|c|c|c}
\hline Participante & $\begin{array}{c}\text { Teclas/min com } \\
\text { TAP }\end{array}$ & $\begin{array}{c}\text { Teclas/min sem } \\
\text { TAP }\end{array}$ & $\begin{array}{c}\text { Teclas de produção } \\
\text { textual/min com TAP }\end{array}$ & $\begin{array}{c}\text { Teclas de produção } \\
\text { textual/min sem TAP }\end{array}$ \\
\hline 5 & 60 & 65 & 51,5 & 54 \\
\hline 6 & 72 & 117 & 47,5 & 82 \\
\hline 7 & 66 & 114,5 & 37,5 & 57 \\
\hline 8 & 63,5 & 81 & 52 & 67,5 \\
\hline 9 & 50,5 & 55,5 & 41 & 39,5 \\
\hline Média & 62,4 & 86,6 & 45,9 & 60 \\
\hline
\end{tabular}

Nota: $\mathrm{TAP}=$ protocolo de verbalização do pensamento em voz alta.

Novamente, o cálculo da média dos valores por minuto nos textos levou aos valores de velocidade com e sem a verbalização mostrados na Tabela 4.

A comparação entre os valores para um mesmo participante mostrou que o uso do TAP desacelerou o processo de todos os participantes no que diz respeito ao número total de acionamentos de teclas. Mais uma vez, os participantes foram afetados de forma bastante diferente (com variação de $8 \%$ a 42\%). Na contagem da produção textual, quatro tradutores expertos também apresentaram produção mais lenta com a verbalização do que sem (com variação de 5\% a 42\%). Ao contrário do esperado, no entanto, um participante realizou sua atividade um pouco mais rapidamente com o TAP do que sem ele $(3,6 \%)$. Esse resultado foi causado pela tradução, excepcionalmente lenta, do texto 1 realizada pelo participante 9 .

Para o grupo como um todo, houve $27,9 \%$ a menos de acionamentos de teclas $(86,6$ contra 62,4$)$ e $23,5 \%$ a menos de teclas de produção textual por minuto na condição de produção com o TAP do que na condição sem o protocolo de verbalização (60 contra 45,9).

\subsection{Comparação entre os grupos}

A velocidade com que os tradutores expertos realizaram suas tarefas resultou em uma produção textual com uma média de 60 acionamentos de teclas por minuto sem verbalização e 46 com verbalização. A média máxima de velocidade de produção textual alcançada em uma tarefa foi de 86 caracteres por minuto; a mínima, de 26. Esses valores máximo e mínimo correspondem respectivamente a algo em torno de 3 laudas e 1 lauda por hora.

O grupo dos semiprofissionais produziu textos bem mais lentamente do que o grupo de tradutores expertos. A velocidade média daquele grupo foi de 48 caracteres por minuto 
sem o TAP e de 37 com a realização do protocolo. A média máxima da velocidade de produção textual alcançada em uma tarefa foi de 67 caracteres por minuto; a mínima, de 23.

Assim, as primeiras duas hipóteses foram confirmadas pelos seguintes resultados: ambos os grupos trabalharam mais rapidamente sem a realização do TAP (22,3\% e 23,5\%); e os tradutores expertos trabalharam mais rapidamente do que os tradutores do último ano de mestrado em tradução (foram 18,6\% mais rápidos com a realização do TAP; e 19,8\% mais rápidos sem a realização do protocolo).

\subsection{Discussão}

A diferença na velocidade da produção textual entre o grupo de tradutores semiprofissionais e o de tradutores expertos foi menor do que o esperado. Quatro fatores principais, sendo dois deles de ordem afetiva, podem ter contribuído para a diminuição do desempenho dos tradutores expertos. Em primeiro lugar, as tarefas de tradução não eram tarefas comuns da área de expertise desses tradutores. Em segundo lugar, em razão de as contagens terem sido efetuadas levando em consideração as tarefas completas, a diferença entre os dois grupos pode ter sido distorcida, ou seja, é possível que os tradutores expertos tenham trabalhado mais rápido do que o que está refletido na estatística geral durante a fase de redação da primeira versão da tradução, gastando mais tempo posteriormente em revisões cuidadosas para a entrega da versão final (cf. JAKOBSEN, 2002, traduzido neste volume). Em terceiro lugar, os tradutores profissionais estavam muito conscientes da situação em que se encontravam, estando alguns até hipersensíveis ou mesmo levemente paranoicos; claramente sentiram o impacto de estar em uma situação artificial, ao passo que os tradutores estudantes estavam mais confortáveis, confiantes e, em geral, mais generosos em suas verbalizações. Em quarto lugar, os tradutores profissionais estavam muito conscientes de que o experimento poderia pôr à prova suas imagens profissionais e, por isso, preferiram evitar se comprometerem.

Esses fatores refletem negativamente sobre a validade ecológica do experimento. Entretanto, o fato é que, sob as condições do experimento e desconsiderando quaisquer diferenças na qualidade das soluções dadas às tarefas, os tradutores profissionais produziram textos apenas $20 \%$ mais rapidamente (em geral) do que os tradutores do último ano de mestrado. 


\subsection{Efeito da direção}

Como mostrado na Tabela 1 (coluna 8: total de teclas/min), cada um dos quatro tradutores semiprofissionais trabalhou mais lentamente na tradução para a L2 do que para a L1 sob a mesma condição de realização do TAP. A diferença média (do grupo) foi de 16,4\%. $\mathrm{Na}$ contagem de teclas de produção textual (coluna 9), três dos quatro participantes trabalharam mais lentamente com a verbalização (entre 14\% e 30\%); porém, um participante produziu 5\% mais texto por minuto, o que reduziu a diferença média de teclas de produção textual do grupo para $13,9 \%$.

A comparação entre valores para um mesmo participante no grupo dos tradutores expertos (Tabela 3) mostrou que todos eles (exceto o participante 9 quando traduziu realizando o TAP) acionaram menos teclas por minuto na tradução para a L2 do que para a L1 (sob a mesma condição de uso do TAP) ${ }^{5}$. No grupo dos expertos em geral - aceitando que a identificação do dinamarquês como L1 do participante 9 é problemática -, a tradução da L1 para L2 foi 15,5\% mais lenta do que da L2 para a L1. Portanto, a primeira metade da hipótese 3 encontrou respaldo nos resultados aqui apresentados.

O raciocínio por trás da segunda metade da hipótese 3 , de que a tradução para a L2 com o TAP seria particularmente mais lenta, era que a verbalização em L1 durante a produção de um texto em L2 causaria interferência ou criaria um conflito de língua que inibiria ou retardaria a produção textual.

No grupo dos tradutores semiprofissionais, houve 23,6\% menos teclas de produção textual para a L2 com o TAP do que sem ele e $8,4 \%$ menos teclas de produção textual com a verbalização para a L2 do que para a L1. De forma similar, no grupo dos tradutores expertos, houve $19,7 \%$ menos teclas de produção textual para a L2 com o TAP do que sem ele e 9,7\% menos teclas de produção textual com a verbalização para a L2 do que para a L1.

Tanto a verbalização como a direção de L1 para L2 retardaram a produção textual. A hipótese de que a tradução para a L2 com verbalização seria particularmente mais lenta encontrou respaldo nos resultados aqui apresentados. Entretanto, podemos apenas especular que a lentidão foi causada pelo conflito entre a verbalização na L1 e a produção textual simultânea na L2.

\footnotetext{
${ }^{5}$ A primeira língua do participante 9 é o inglês, embora o dinamarquês tenha sido relatado como sendo a língua predominante. Os valores para o desempenho do participante 9 nas tarefas sugerem que a identificação do dinamarquês como L1 para esse participante é enganosa.
} 
4.6 Análise de variância (ANOVA) para os efeitos sobre a velocidade

Os dados para a variável velocidade foram submetidos uma análise de variância $2 \times 2 \times 2$. Os três fatores dessa análise foram: expertise (semiprofissionais contra expertos), verbalização concomitante à tradução (com e sem TAP) e direcionalidade (L1 $\rightarrow$ L2 ou $\mathrm{L} 2 \rightarrow \mathrm{L} 1)$.

A análise mostrou que dois dos três fatores tiveram efeito significativo. A expertise não teve efeito significativo sobre a velocidade (42,75 para os semiprofissionais contra 52,95 para os expertos, $F(1,7)=1,72, p>0,05)$. Entretanto, a velocidade foi maior sem TAP do que com verbalização $(54,06$ contra $41,63, \mathrm{~F}(1,7)=8,97 ; \mathrm{p}=0,02)$ e maior nas traduções para a L1 do que naquelas para a L2 (51,82 contra 43,87; $\mathrm{F}(1,7)=14,16 ; \mathrm{p}=0,007)$. Além disso, a interação entre verbalização e direcionalidade não foi significativa; porém, a análise dos efeitos simples mostrou que a desaceleração causada pela verbalização foi significativa apenas para a tradução da L2 para a L1 $(44,67$ contra 58,97; $F(1,7)=15,05 ; p=0,006)$.

Em suma:

- a verbalização desacelerou a produção do texto-alvo (TA); tanto na tradução da L2 para a L1 como da L1 para a L2, seja no grupo dos semiprofissionais ou expertos, o processo foi mais lento quando realizado com o TAP;

- os tradutores profissionais realizaram suas atividades mais rapidamente (em uma média geral de $20 \%$ ) do que os tradutores do último ano de mestrado em tradução (semiprofissionais), mas os dados do experimento foram insuficientes para mostrar se essa diferença foi estatisticamente significativa;

- a tradução da L1 para a L2 foi em torno de 16\% mais lenta em ambos os grupos do que a tradução da L2 para a L1. O efeito de desaceleração da verbalização foi maior na direção da L1 para L2 do que na direção L2 para L1, mas nenhuma interação significativa da verbalização com a direcionalidade foi encontrada.

Esses resultados concernentes à desaceleração ocasionada pela realização do TAP não surpreendem. Ericsson e Simon (1993) mencionam explicitamente que poderia haver tal efeito se a verbalização tiver que ser sequenciada. Com a metodologia aplicada aos experimentos deste estudo, podemos dizer mais exatamente (i) que houve realmente uma desaceleração e (ii) que esse efeito teve diferentes impactos em diferentes situações. Ainda que isso nos dê um conhecimento novo e mais preciso sobre a situação da pesquisa em

\footnotetext{
${ }^{6}$ A análise de variância (ANOVA) foi gentilmente realizada por R. J. Jarvella.
} 
tradução, não refuta de modo algum a hipótese fundamental de Ericsson e Simon (1993) de que a verbalização, embora possa desacelerar a atividade mental primária, não altera estruturalmente a atividade ou o processo que se escrutiniza.

Para analisarmos esse pressuposto mais de perto, investigaram-se duas características adicionais na produção do texto-alvo a partir de sua gravação pelo programa Translog, quais sejam: a quantidade de revisão feita com e sem TAP e o número de segmentos de produção textual encontrados nas tarefas com e sem a verbalização. Uma maior quantidade de revisão em uma das condições indicaria uma diferença na quantidade de processamento envidado, enquanto diferentes práticas de revisão sob uma das condições podem indicar uma diferença no tipo ou na qualidade do processamento envidado. Ademais, se a segmentação em uma das condições se mostrar diferente daquela encontrada na outra condição, tem-se que os processamentos nas duas condições não podem ser considerados idênticos.

\section{Efeitos sobre a revisão}

A maior da produção textual envolve muita edição ou revisão. Algumas revisões consistem em meras correções de erros de digitação, mas geralmente há também mudanças mais substanciais na forma ou no conteúdo. Algumas revisões são feitas enquanto a tradução é produzida, como revisão "online" (em tempo real, imediata); outras, depois que a primeira versão da tradução está completa, como revisão “final” (KRINGS, 2001; MOSSOP, 2001).

A análise das amostras de alguns arquivos de registro do Translog sugeriu que a verbalização pode ocasionar diversos efeitos. Em alguns arquivos, a verbalização pareceu afetar negativamente o processo de digitação, como, por exemplo, provocando mais erros de digitação. Isso sugere que a verbalização adicionou sobrecarga cognitiva ao tradutor, o que tornou a digitação mais difícil. Em outros arquivos, a realização do TAP pareceu provocar mais mudanças de ordem semântica durante a revisão e ter um efeito positivo sobre a revisão do conteúdo. Isso sugere que a informação audível advinda da própria verbalização do participante teve um efeito de estímulo a adequações semânticas e, finalmente, pode ter um efeito positivo na qualidade da tradução (BADDELEY et al., 1998).

O desafio, do ponto de vista do presente estudo, foi encontrar indícios estatísticos para qualquer uma dessas ideias sem recurso à análise qualitativa. $\mathrm{O}$ fragmento da Figura 1 (obtido pelo Translog, mas exibido sem a maior parte da informação temporal) pode ser utilizado para ilustrar algumas das dificuldades em encontrar a forma mais adequada de se proceder a essa análise e mostrar a diferença entre as três contagens de revisão realizadas no presente estudo. 
Figura 1 - Excerto do arquivo registrado com o Translog.

Acionamentos de teclas registrados:

$60, \bullet 0000 \otimes \bullet$ people $*$ were witnessing $\otimes \otimes \otimes \otimes \otimes \otimes \otimes \otimes \otimes$ watching $\star_{\text {an }} \bullet . . .$. between ${ }^{*}$ the $\bullet$ two $\bullet$ largest $\bullet$ soccer $\bullet$ clubs $\bullet$ in $\bullet$ Uruga $\otimes$ uay $\bullet$ the $\bullet$ rivals $\bullet$ Pefiarola $\otimes \bullet$ and $\bullet$ Nacional $[\mathrm{Crr} i \leftarrow][\mathrm{Ctrl} \leftarrow][\mathrm{Ctr}] \leftarrow]$

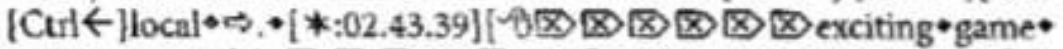

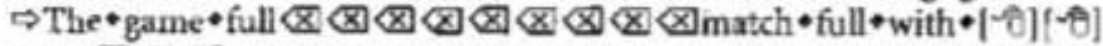

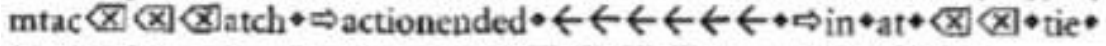
$(1-1) \bullet$ after $\bullet$ several $\bullet$ entertaining $\otimes \otimes \otimes \otimes$ ning $\bullet[*: 01.22 .24]$ moments.

Versão final do texto-alvo:

60,000 people were watching an exciting match between the two largest soccer clubs in Uruguay - the local rivals Peñarol and Nacional. The match full with action ended in a tie (1-1) after several entertaining moments.

Glosa:

60. 000 pessoas assistiam a uma emocionante partida entre os dois maiores times de futebol do Uruguai - os rivais locais Peñarol e Nacional. Está partida, repleta de ação, terminou em empate (1-1) após vários momentos de entretenimento.

Nesse exemplo, o participante digitou primeiro, acidentalmente, um zero a mais, o qual instantaneamente excluiu (凶). A inserção acidental de um espaço no número após a vírgula (indicativa de milhar em inglês) passou despercebida. Imediatamente após digitar "60, 000 people were witnessing", o participante excluiu "witnessing" [gerúndio de "testemunhar"] e substituiu por "watching" [gerúndio de "assistir"]. Depois, o participante digitou "an" [artigo indefinido] seguido de seis pontos, indicando que deixara o problema sem solução naquele momento. Em seguida, erros de digitação em "Uruguay" e em "Peñarol" foram corrigidos imediatamente após as palavras terem sido digitadas. Então, seguiu um movimento de navegação do cursor (Control + seta para a esquerda) para inserir o adjetivo "local", seguido da tecla $\Rightarrow$ (End) para levar o cursor de volta ao final da linha. Após trabalhar por mais de 2,5 min na busca por uma solução para substituir os seis pontos anteriores, o participante os excluiu e inseriu "exciting game" ["jogo emocionante"]. Depois, "game full" [“jogo repleto"] foi excluído e substituído por "match full" ["partida repleta"]. Em seguida, "game" ["jogo"] foi marcado com o mouse e substituído por "match" ["partida"] (após outro erro de digitação ter sido corrigido). Mais tarde, novamente, a tecla de seta para a esquerda foi pressionada seis vezes, e um espaço foi inserido entre "action" ["ação"] e "ended" [passado de "terminar"]. Finalmente, após outro pequeno erro de digitação, o final de "ning”, em "entertaining" [adjetivo "que causa entretenimento"], foi excluído (indicando que outra solução fora contemplada), mas subsequentemente redigitado. 
Do ponto de vista da pesquisa, esses diferentes tipos de atividade de digitação não são igualmente interessantes. As decisões de mudar o verbo "witnessing" para "watching" e o substantivo "game" para "match", de adiar a tradução de um elemento (evidenciada pelos pontos) e de inserir o adjetivo "local" são mais importantes que o fato de o participante ter acidentalmente pressionado as teclas " $l$ " e " $e$ ", que são próximas no teclado dinamarquês. Entretanto, o fato de o erro ter sido instantaneamente descoberto, como evidenciado pela imediata exclusão de " $\propto$ ", é importante do ponto de vista da análise do processamento, pois indica como o tradutor monitorou sua digitação com atenção.

O Translog, infelizmente, é incapaz de fazer distinção entre as digitações que são mais ou menos relevantes. A versão experimental do Translog usada neste estudo contabilizou todos os acionamentos de teclas assim como todos os caracteres de produção textual (incluindo-se, por exemplo, espaços, mas excluindo-se os movimentos de cursor, os cliques no mouse e as teclas de exclusão). Uma contagem óbvia, portanto, foi a subtração do número de teclas de produção textual (teclas de produção textual) do número total de acionamentos de teclas (total de teclas). Essa diferença entre o número total de acionamentos de teclas e o número de teclas de produção textual corresponde quase inteiramente às teclas de exclusão, aos movimentos de cursor, aos cliques no mouse e a similares, ou seja, indica teclas que podem ser atribuídas de forma inequívoca à atividade de revisão textual.

Os valores relevantes para o fragmento apresentado na Figura 1 são: total de teclas $=317$; teclas de produção textual $=252$. Subtraindo as teclas de produção textual do total de teclas, dividindo o resultado pelo total de teclas e multiplicando por 100, obtém-se o percentual (Rev1) de acionamentos de teclas ligados à atividade de revisão envidada pelo participante. Em outros termos, tem-se a fórmula: ((Total de teclas - teclas de produção textual) / Total de teclas) x 100 .

Entretanto, embora esses valores indiquem aspectos do comportamento de digitação do participante em relação à revisão, eles não capturam verdadeiramente o fato de que a revisão não envolve apenas, em termos textuais, a exclusão dos caracteres normais e a navegação do cursor; envolve, também, a digitação de novos caracteres- não menos normais do que aqueles substituídos. Para capturar esse aspecto textual da revisão, um novo cálculo foi feito (Rev2) baseado na contagem das diferenças entre o número de teclas de produção textual e os caracteres (e espaços) no texto-alvo final (caracteres do TA). A revisão foi aqui calculada como qualquer caractere digitado em adição àqueles da versão final do texto-alvo. A fórmula é: ((teclas de produção textual - caracteres do TA) / teclas de produção textual) x 100. 
A comparação entre Rev1 e Rev2 forneceria uma noção da eficiência dos movimentos do participante durante a revisão. Todavia, somente uma análise manual minuciosa dos arquivos do Translog possibilitaria identificar que parte da revisão textual correspondeu a uma simples correção de erros de digitação e que parte foi resultado de uma reflexão sobre a tradução.

A terceira contagem feita (Rev3) é apenas uma junção da Rev1 e Rev2 em um único valor. A fórmula é: ((Total de teclas - caracteres do TA)/Total de teclas) x 100. Uma contagem relacionando os acionamentos de teclas ligados à revisão com o número de caracteres do texto-fonte foi levada em consideração, mas descartada como irrelevante.

Os valores para a revisão (Rev1) para o grupo dos semiprofissionais são mostrados na Tabela 5 .

Tabela 5 - Acionamentos de teclas pelo grupo dos semiprofissionais com as porcentagens de Rev1 e médias por texto, direção, realização do TAP e participante

\begin{tabular}{|c|c|c|c|c|c|c|c|c|c|}
\hline Part. & Texto & $\begin{array}{c}\text { Condição } \\
\text { (TAP) }\end{array}$ & $\begin{array}{c}\text { Total de } \\
\text { teclas }\end{array}$ & $\begin{array}{c}\text { Teclas de } \\
\text { produção } \\
\text { textual }\end{array}$ & Rev1 \% & $\begin{array}{c}\text { Média } \\
\text { por } \\
\text { texto }\end{array}$ & $\begin{array}{c}\text { Por } \\
\text { direção }\end{array}$ & $\begin{array}{l}\text { Por uso } \\
\text { do TAP }\end{array}$ & Por part. \\
\hline 1 & 2 & Sem TAP & 704 & 632 & 10,2 & & & & \\
\hline 2 & 2 & Sem TAP & 937 & 693 & 26,0 & & & & \\
\hline 3 & 2 & Sem TAP & 710 & 550 & 22,5 & Txtl & & & S1 \\
\hline 4 & 2 & Sem TAP & 1078 & 759 & 29,6 & 23,0 & & & 16,9 \\
\hline 1 & 3 & Sem TAP & 1062 & 822 & 22,6 & & & & \\
\hline 2 & 3 & Sem TAP & 1278 & 1053 & 17,6 & & & & \\
\hline 3 & 3 & Sem TAP & 1214 & 916 & 24,5 & Txt2 & $\mathrm{L} 1 \rightarrow \mathrm{L} 2$ & Sem TAP & S2 \\
\hline 4 & 3 & Sem TAP & 1556 & 1078 & 30,7 & 22,1 & 22,6 & 23,0 & 23,5 \\
\hline 1 & 1 & Com TAP & 560 & 461 & 17,7 & & & & \\
\hline 2 & 1 & Com TAP & 863 & 631 & 26,9 & & & & \\
\hline 3 & 1 & Com TAP & 1044 & 726 & 30,5 & Txt3 & & & S3 \\
\hline 4 & 1 & Com TAP & 601 & 498 & 17,1 & 23,9 & & & 24,0 \\
\hline 1 & 4 & Com TAP & 1311 & 1089 & 16,9 & & & & \\
\hline 2 & 4 & Com TAP & 2209 & 1690 & 23,5 & & & & \\
\hline 3 & 4 & Com TAP & 1524 & 1245 & 18,3 & Txt4 & $\mathrm{L} 2 \rightarrow \mathrm{L} 2$ & $\begin{array}{l}\text { Com } \\
\text { TAP }\end{array}$ & S4 \\
\hline 4 & 4 & Com TAP & 2175 & 1276 & 41,3 & 25,0 & 24,4 & 24,0 & 29,7 \\
\hline
\end{tabular}

Nota: Part.=participante; TAP=protocolo de verbalização do pensamento em voz alta.

Por meio dessa contagem, a média da quantidade de revisão a cada 100 acionamentos de teclas nos quatro textos foi de 23,5 (com variação de 22,1 a 25,0). Ao contrário do que se 
esperava, o valor para a revisão na direção $\mathrm{L} 1 \rightarrow \mathrm{L} 2$ foi menor (embora apenas ligeiramente) do que aquele na direção $\mathrm{L} 2 \rightarrow \mathrm{L} 1$. O valor para a revisão feita com verbalização $(24,0)$ foi maior do que aquele para a revisão sem verbalização $(23,0)$, mas, novamente, apenas ligeiramente.

A principal diferença foi claramente no estilo individual dos participantes. As quantidades de texto revisadas pelos participantes 1 e 4 foram, respectiva e significativamente, menor e maior que aquelas dos participantes 2 e 3 . A quantidade de acionamentos de teclas relacionados à atividade de revisão do participante 4 foi quase duas vezes maior que aquela do participante 1 .

Os valores obtidos a partir do segundo cálculo (Rev2) para o grupo dos semiprofissionais estão reproduzidos na Tabela 6. Embora os valores de Rev2 tenham sido maiores na direção $\mathrm{L} 1 \rightarrow \mathrm{L} 2$ do que na direção inversa e na condição com verbalização do que na condição sem TAP, não foram identificados efeitos significativos para as variáveis texto, direcionalidade e uso de TAP.

Tabela 6 - Teclas de produção textual e caracteres do texto-alvo final para os participantes 1 a 4 , com a porcentagem de Rev2 e médias por texto, direção, realização do TAP e participante

\begin{tabular}{|c|c|c|c|c|c|c|c|c|c|}
\hline Part. & Texto & $\begin{array}{l}\text { Condição } \\
\text { (TAP) }\end{array}$ & $\begin{array}{l}\text { Teclas de } \\
\text { produçã } \\
\text { o textual }\end{array}$ & $\begin{array}{c}\text { Caracteres } \\
\text { do TA }\end{array}$ & $\begin{array}{c}\text { Rev2 } \\
\%\end{array}$ & $\begin{array}{l}\text { Média } \\
\text { por } \\
\text { texto }\end{array}$ & $\begin{array}{c}\text { Por } \\
\text { direção }\end{array}$ & $\begin{array}{l}\text { Por uso } \\
\text { do TAP }\end{array}$ & $\begin{array}{l}\text { Por } \\
\text { part. }\end{array}$ \\
\hline 1 & 2 & Sem TAP & 632 & 595 & 5,9 & & & & \\
\hline 2 & 2 & Sem TAP & 693 & 511 & 26,3 & & & & \\
\hline 3 & 2 & Sem TAP & 550 & 465 & 15,5 & Txtl & & & S1 \\
\hline 4 & 2 & Sem TAP & 759 & 629 & 17,1 & 21,4 & & & 8,7 \\
\hline 1 & 3 & Sem TAP & 822 & 734 & 10,7 & & & & \\
\hline 2 & 3 & Sem TAP & 1053 & 870 & 17,4 & & & & \\
\hline 3 & 3 & Sem TAP & 916 & 797 & 13,0 & Txt2 & $\mathrm{L} 1 \rightarrow \mathrm{L} 2$ & $\begin{array}{l}\text { Sem } \\
\text { TAP }\end{array}$ & S2 \\
\hline 4 & 3 & Sem TAP & 1078 & 854 & 20,8 & 16,2 & 18,8 & 15,8 & 24,3 \\
\hline 1 & 1 & Com TAP & 461 & 412 & 10,6 & & & & \\
\hline 2 & 1 & Com TAP & 631 & 488 & 22,7 & & & & \\
\hline 3 & 1 & Com TAP & 726 & 441 & 39,3 & Txt3 & & & S3 \\
\hline 4 & 1 & Com TAP & 498 & 433 & 13,1 & 15,5 & & & 19,9 \\
\hline 1 & 4 & Com TAP & 1089 & 1006 & 7,6 & & & & \\
\hline 2 & 4 & Com TAP & 1690 & 1170 & 30,8 & & & & \\
\hline 3 & 4 & Com TAP & 1245 & 1097 & 11,9 & Txt4 & $\mathrm{L} 2 \rightarrow \mathrm{L} 1$ & $\begin{array}{l}\text { Com } \\
\text { TAP }\end{array}$ & S4 \\
\hline 4 & 4 & Com TAP & 1276 & 1132 & 11,3 & 15,4 & 15,4 & 18,4 & 15,6 \\
\hline
\end{tabular}

Nota: Part.=participante; TAP=protocolo de verbalização do pensamento em voz alta. 
Considerando Rev1, os textos 1, 2 e 3 tenderam a ser menos revisados do que o texto 4; entretanto, tomando por base Rev2, foram os textos 2, 3 e 4 que apresentaram os valores mais baixos. Mais uma vez, a diferença maior foi verificada na variável participante.

O participante 1, novamente, foi o participante que realizou menos revisões textuais. Esse participante ou não produziu muitas soluções, ou preferiu não se expor à memória eletrônica do programa até que uma melhor solução fosse encontrada. Em contrapartida, os participantes 2 e 3 revisaram quase três vezes mais do que o participante quando se leva em conta Rev2, o que ilustra uma abordagem de produção textual bem diferente. Com habilidades de digitação e edição superiores, esses participantes optaram por digitar suas ideias assim que surgiam em vez de esperar para garantir que não precisassem ser revisadas depois. $\mathrm{O}$ valor do participante 4 para Rev2 o levou à posição mais baixa (terceiro lugar). O valor elevado para Rev1 e mais baixo para Rev2 é um reflexo da grande quantidade de movimentação do cursor feita pelo participante 4, movimentação essa que não resultou em produção textual. Embora o participante 1 tenha efetuado menos revisão no geral, esse participante fez o dobro de revisão Rev1 em relação a Rev2; em contrapartida, os participantes 2 e 3 fizeram quase a mesma quantidade de revisão considerando Rev1 e Rev2. 
Tabela 7 - Junção dos valores de revisão (Rev3) para o grupo dos semiprofissionais

\begin{tabular}{|c|c|c|c|c|c|c|c|c|c|c|c|}
\hline Part. & Texto & Tarefa & $\begin{array}{c}\text { Condição } \\
\text { (TAP) }\end{array}$ & $\begin{array}{c}\text { Total de } \\
\text { teclas }\end{array}$ & $\begin{array}{c}\text { Caracteres } \\
\text { do TA }\end{array}$ & Rev3 \% & $\begin{array}{l}\text { Média } \\
\text { por } \\
\text { texto }\end{array}$ & $\begin{array}{c}\text { Por } \\
\text { direção }\end{array}$ & $\begin{array}{l}\text { Por uso } \\
\text { do TAP }\end{array}$ & $\begin{array}{l}\text { Por } \\
\text { part. }\end{array}$ & $\begin{array}{c}\text { Por } \\
\text { tarefa }\end{array}$ \\
\hline 1 & 2 & 1 & Sem TAP & 704 & 595 & 15,5 & & & & & \\
\hline 2 & 2 & 3 & Sem TAP & 937 & 511 & 45,5 & & & & & \\
\hline 3 & 2 & 2 & Sem TAP & 710 & 465 & 34,5 & Txtl & & & S1 & Tarefa1 \\
\hline 4 & 2 & 4 & Sem TAP & 1078 & 629 & 41,7 & 38,9 & & & 24,0 & 41,3 \\
\hline 1 & 3 & 4 & Sem TAP & 1062 & 734 & 30,9 & & & & & \\
\hline 2 & 3 & 2 & Sem TAP & 1278 & 870 & 31,9 & & & & & \\
\hline 3 & 3 & 3 & Sem TAP & 1214 & 797 & 34,3 & Txt2 & $\mathrm{L} 1 \rightarrow \mathrm{L} 2$ & $\begin{array}{l}\text { Sem } \\
\text { TAP }\end{array}$ & S2 & Tarefa2 \\
\hline 4 & 3 & 1 & Sem TAP & 1556 & 854 & 45,1 & 34,3 & 36,6 & 34,9 & 42,0 & 35,2 \\
\hline 1 & 1 & 2 & Com TAP & 560 & 412 & 26,4 & & & & & \\
\hline 2 & 1 & 4 & Com TAP & 863 & 488 & 43,5 & & & & & \\
\hline 3 & 1 & 1 & Com TAP & 1044 & 441 & 57,8 & Txt3 & & & S3 & Tarefa3 \\
\hline 4 & 1 & 3 & Com TAP & 601 & 433 & 28,0 & 35,6 & & & 38,7 & 32,8 \\
\hline 1 & 4 & 3 & Com TAP & 1311 & 1006 & 23,3 & & & & & \\
\hline 2 & 4 & 1 & Com TAP & 2209 & 1170 & 47,0 & & & & & \\
\hline 3 & 4 & 4 & Com TAP & 1524 & 1097 & 28,0 & Txt4 & $\mathrm{L} 2 \rightarrow \mathrm{L} 1$ & $\begin{array}{l}\text { Com } \\
\text { TAP }\end{array}$ & S4 & Tarefa4 \\
\hline 4 & 4 & 2 & Com TAP & 2175 & 1132 & 48,0 & 36,6 & 36,0 & 37,7 & 40,7 & 36,0 \\
\hline
\end{tabular}

Nota: Part.=participante; TAP=protocolo de verbalização do pensamento em voz alta.

Tanto Rev1 quanto Rev2 capturam aspectos relevantes da revisão, e existe o risco de que essas nuances fiquem despercebidas com a junção das duas em um único cálculo (Rev3), como mostra a Tabela 7.

A principal diferença nessa contagem continua sendo o comportamento individual de revisão dos participantes. Nessa contagem, os hábitos de revisão do participante 4 são alinhados, de uma forma que não reflete a realidade, com os dos participantes 2 e 3 , ao passo que o participante 1 continuou se destacando por sua significativa revisão abaixo da média.

As médias por tarefa foram incluídas nessa contagem. Elas sugerem que a sequência das tarefas pode ter afetado ligeiramente o comportamento de revisão. Os participantes tenderam a revisar mais no início, passando a revisar cada vez menos e, por fim, um pouco mais, sendo esse talvez um indicativo de que começavam a se cansar. O valor para a revisão da tradução da L1 $\rightarrow$ L2 $(36,6)$ foi, mais uma vez, apenas ligeiramente maior do que da L2 $\rightarrow$ L1 $(36,0)$. O valor para a revisão com TAP $(37,7)$ foi apenas ligeiramente maior do que aquele na tarefa sem TAP $(34,9)$. 
A comparação entre as tarefas realizadas por um mesmo participante apresentou um resultado sem tendências claras. Duas das traduções para a L2 (inglês) feitas com verbalização apresentaram mais revisão do que as traduções para a L2 produzidas sem verbalização, e duas apresentaram menos. Duas das traduções para a L1 (dinamarquês) realizadas com verbalização apresentaram mais revisão do que as traduções para L1 executadas sem verbalização; e, também, duas apresentaram menos.

Os valores para o grupo dos tradutores expertos foram apenas ligeiramente diferentes, sendo que a ordem da tarefa foi omitida porque não ocasionara efeitos. Os valores para Rev1 são aqueles registrados na Tabela 8. No caso, as médias por texto foram bastante uniformes (com variação de 25,2 a 29,0), e as médias por direcionalidade foram praticamente idênticas (com variação de 27,0 a 27,1). Assim como no grupo dos semiprofissionais, a realização do TAP não causou efeito significativo, mas, contrariamente ao que ocorreu no primeiro grupo, os tradutores expertos revisaram um pouco mais sem a verbalização do que com. Novamente, a diferença maior foi verificada na variável participante: o 7 revisou quase três vezes mais do que os participantes 5 e 8 . 
Tabela 8 - Acionamentos de teclas para o grupo de tradutores expertos, com as porcentagens de Rev1 e as médias por texto, direção, realização do TAP e participante

\begin{tabular}{|c|c|c|c|c|c|c|c|c|c|}
\hline Part. & Texto & $\begin{array}{c}\text { Condição } \\
\text { (TAP) }\end{array}$ & $\begin{array}{c}\text { Total de } \\
\text { teclas }\end{array}$ & $\begin{array}{l}\text { Teclas de } \\
\text { produçã } \\
\text { o textual }\end{array}$ & Rev1 \% & $\begin{array}{l}\text { Média } \\
\text { por } \\
\text { texto }\end{array}$ & $\begin{array}{c}\text { Por } \\
\text { direção }\end{array}$ & $\begin{array}{l}\text { Por uso } \\
\text { do TAP }\end{array}$ & Por part. \\
\hline 5 & 1 & Sem TAP & 638 & 510 & 20,1 & & & & \\
\hline 6 & 1 & Sem TAP & 754 & 527 & 30,1 & & & & \\
\hline 7 & 1 & Sem TAP & 1410 & 745 & 47,2 & & & & S5 \\
\hline 8 & 1 & Sem TAP & 519 & 442 & 14,8 & Txtl & & & 15,7 \\
\hline 9 & 1 & Sem TAP & 597 & 455 & 23,8 & 27,2 & & & \\
\hline 5 & 4 & Sem TAP & 1474 & 1277 & 13,4 & & & & \\
\hline 6 & 4 & Sem TAP & 1955 & 1368 & 30,0 & & & & S6 \\
\hline 7 & 4 & Sem TAP & 3732 & 1788 & 52,1 & & & & 31,9 \\
\hline 8 & 4 & Sem TAP & 1697 & 1396 & 17,7 & Txt2 & $\mathrm{L} 1 \rightarrow \mathrm{L} 2$ & Sem TAP & \\
\hline 9 & 4 & Sem TAP & 2100 & 1434 & 31,7 & 26,8 & 27,0 & 28,1 & \\
\hline 5 & 2 & Com TAP & 711 & 600 & 15,6 & & & & S7 \\
\hline 6 & 2 & Com TAP & 1074 & 731 & 31,9 & & & & 47,1 \\
\hline 7 & 2 & Com TAP & 1422 & 753 & 47,0 & & & & \\
\hline 8 & 2 & Com TAP & 852 & 678 & 20,4 & Txt3 & & & \\
\hline 9 & 2 & Com TAP & 750 & 609 & 18,8 & 25,2 & & & S8 \\
\hline 5 & 3 & Com TAP & 1120 & 967 & 13,7 & & & & 17,1 \\
\hline 6 & 3 & Com TAP & 1524 & 981 & 35,6 & & & & \\
\hline 7 & 3 & Com TAP & 1972 & 1143 & 42,0 & & & & \\
\hline 8 & 3 & Com TAP & 1143 & 965 & 15,6 & Txt4 & $\mathrm{L} 2 \rightarrow \mathrm{L} 1$ & $\begin{array}{l}\text { Com } \\
\text { TAP }\end{array}$ & s9 \\
\hline 9 & 3 & Com TAP & 1183 & 956 & 19,2 & 29,0 & 27,1 & 26,0 & 23,4 \\
\hline
\end{tabular}

Nota: Part.=participante; TAP=protocolo de verbalização do pensamento em voz alta.

Os valores para Rev2 no grupo dos expertos estão registrados na Tabela 9. O maior efeito foi, novamente, a variância entre os participantes. Os participantes 5 e 8 (e 9) produziram as menores quantidades de texto que não foi utilizado na versão final do textoalvo, ao passo que o participante 7 pareceu ser uma espécie de revisor compulsivo ou ter integrado a revisão ao seu método de trabalho.

Embora tenha havido algumas diferenças considerando a variável texto, elas foram muito pequenas para serem estatisticamente significativas. Da mesma forma, o efeito da direcionalidade na revisão não foi significativo. Houve apenas uma pequena quantidade a mais de revisão textual quando os participantes trabalharam da L1 para a L2. O grupo dos tradutores expertos realizou uma quantidade consideravelmente maior de revisão textual quando trabalhou com o TAP do que sem ele. Infelizmente, não foi possível (pela abordagem 
estatística aqui adotada) calcular até que ponto esse efeito se deu devido a uma maior ocorrência de correção de erros de digitação na tradução realizada com o uso de TAP - o que indicaria que a verbalização acrescenta sobrecarga cognitiva à tarefa - ou devido a um maior número de opções semânticas ter sido considerado em decorrência do retorno fonológico da própria verbalização do participante.

Tabela 9 - Teclas de produção textual e caracteres do texto-alvo final para os participantes de 5 a 9, com os percentuais da Rev2 e médias por texto, direção, realização do TAP e participante

\begin{tabular}{|c|c|c|c|c|c|c|c|c|c|}
\hline Part. & Texto & $\begin{array}{l}\text { Condição } \\
\text { (TAP) }\end{array}$ & $\begin{array}{c}\text { Teclas de } \\
\text { produção } \\
\text { textual }\end{array}$ & $\begin{array}{c}\text { Caracteres } \\
\text { do TA }\end{array}$ & Rev2 \% & $\begin{array}{c}\text { Média por } \\
\text { texto }\end{array}$ & $\begin{array}{c}\text { Por } \\
\text { direção }\end{array}$ & $\begin{array}{c}\text { Por uso do } \\
\text { TAP }\end{array}$ & Por part. \\
\hline 5 & 1 & Sem TAP & 510 & 399 & 21,8 & & & & \\
\hline 6 & 1 & Sem TAP & 527 & 393 & 25,4 & & & & \\
\hline 7 & 1 & Sem TAP & 745 & 446 & 40,1 & & & & S5 \\
\hline 8 & 1 & Sem TAP & 442 & 391 & 11,5 & Txtl & & & 13,6 \\
\hline 9 & 1 & Sem TAP & 455 & 387 & 14,9 & 22,8 & & & \\
\hline 5 & 4 & Sem TAP & 1277 & 1134 & 11,2 & & & & \\
\hline 6 & 4 & Sem TAP & 1365 & 1113 & 18,6 & & & & S6 \\
\hline 7 & 4 & Sem TAP & 1788 & 1164 & 34,9 & & & & 23,7 \\
\hline 8 & 4 & Sem TAP & 1396 & 1166 & 16,5 & Txt2 & $\mathrm{L} 1 \rightarrow \mathrm{L} 2$ & Sem TAP & \\
\hline 9 & 4 & Sem TAP & 1434 & 1105 & 22,9 & 18,0 & 20,4 & 17,3 & \\
\hline 5 & 2 & Com TAP & 600 & 532 & 11,3 & & & & S7 \\
\hline 6 & 2 & Com TAP & 731 & 518 & 29,1 & & & & 33,0 \\
\hline 7 & 2 & Com TAP & 753 & 541 & 28,2 & & & & \\
\hline 8 & 2 & Com TAP & 678 & 605 & 10,8 & Txt3 & & & \\
\hline 9 & 2 & Com TAP & 609 & 545 & 10,5 & 16,7 & & & S8 \\
\hline 5 & 3 & Com TAP & 967 & 870 & 10,0 & & & & 12,4 \\
\hline 6 & 3 & Com TAP & 981 & 771 & 21,4 & & & & \\
\hline 7 & 3 & Com TAP & 1143 & 813 & 28,9 & & & & \\
\hline 8 & 3 & Com TAP & 965 & 860 & 10,9 & Txt4 & $\mathrm{L} 2 \rightarrow \mathrm{L} 1$ & Com TAP & S9 \\
\hline 9 & 3 & Com TAP & 956 & 839 & 12,2 & 20,8 & 18,8 & 21,8 & 15,2 \\
\hline
\end{tabular}

Nota: Part.=participante; TA=texto-alvo; TAP=protocolo de verbalização do pensamento em voz alta.

As nuances reveladas nos valores de Rev1 e Rev2 desapareceram quando agregadas nos valores de Rev3 na Tabela 10. Considerando os valores agregados por participante, fica confirmada a impressão sobre o estilo de trabalho do participante 7, que envolve revisão bem acima da média, mas oculta a importante distribuição da revisão observada em termos de Rev1 e de Rev2. 
Tabela 10 - Valores de revisão agregados (Rev3) para o grupo dos tradutores expertos

\begin{tabular}{|c|c|c|c|c|c|c|c|c|c|}
\hline Part. & Texto & $\begin{array}{c}\text { Condição } \\
\text { (TAP) }\end{array}$ & \begin{tabular}{|c} 
Total de \\
teclas
\end{tabular} & $\begin{array}{c}\text { Caracteres } \\
\text { do TA }\end{array}$ & Rev3 \% & \begin{tabular}{|c}
$\begin{array}{c}\text { Média por } \\
\text { texto }\end{array}$ \\
\end{tabular} & Por direção & $\begin{array}{c}\text { Por uso do } \\
\text { TAP } \\
\end{array}$ & Por part. \\
\hline 5 & 1 & Sem TAP & 638 & 399 & 37,5 & & & & \\
\hline 6 & 1 & Sem TAP & 754 & 393 & 47,9 & & & & \\
\hline 7 & 1 & Sem TAP & 1410 & 446 & 68,4 & Txt1 & & & S5 \\
\hline 8 & 1 & Sem TAP & 519 & 391 & 24,7 & 42,7 & & & 27,0 \\
\hline 9 & 1 & Sem TAP & 597 & 387 & 35,2 & & & & \\
\hline 5 & 4 & Sem TAP & 1474 & 1134 & 23,1 & & & & \\
\hline 6 & 4 & Sem TAP & 1955 & 1113 & 43,1 & & & & S6 \\
\hline 7 & 4 & Sem TAP & 3732 & 1164 & 68,8 & Txt2 & & & 48,0 \\
\hline 8 & 4 & Sem TAP & 1697 & 1166 & 31,3 & 39,0 & $\mathrm{~L} 1 \rightarrow \mathrm{L} 2$ & Sem TAP & \\
\hline 9 & 4 & Sem TAP & 2100 & 1105 & 47,4 & & 40,9 & 42,7 & \\
\hline 5 & 2 & Com TAP & 711 & 532 & 25,2 & & & & S7 \\
\hline 6 & 2 & Com TAP & 1074 & 518 & 51,8 & & & & 64,5 \\
\hline 7 & 2 & Com TAP & 1422 & 541 & 62,0 & Txt3 & & & \\
\hline 8 & 2 & Com TAP & 852 & 605 & 29,0 & 36,9 & & & \\
\hline 9 & 2 & Com TAP & 750 & 545 & 27,3 & & & & S8 \\
\hline 5 & 3 & Com TAP & 1120 & 870 & 22,3 & & & & 27,4 \\
\hline 6 & 3 & Com TAP & 1524 & 771 & 49,4 & & & & \\
\hline 7 & 3 & Com TAP & 1972 & 813 & 58,8 & Txt4 & & & \\
\hline 8 & 3 & Com TAP & 1143 & 860 & 24,8 & 42,7 & $\mathrm{~L} 2 \rightarrow \mathrm{L} 1$ & Com TAP & S9 \\
\hline 9 & 3 & Com TAP & 1183 & 839 & 29,1 & & 39,8 & 38,0 & 34,7 \\
\hline
\end{tabular}

Nota: Part.=participante; TA=texto-alvo; TAP=protocolo de verbalização do pensamento em voz alta.

\subsection{Comparação entre os grupos}

Os valores na Rev1 (Tabelas 5 e 8) mostram que o grupo dos tradutores expertos navegou o cursor (ou excluiu mais texto) um pouco mais do que o grupo dos semiprofissionais $(27,1$ contra 23,5$)$, independentemente do texto e da realização, ou não, do TAP. Esse resultado vai ao encontro dos valores obtidos para velocidade. Os tradutores expertos trabalham mais rápido do que os semiprofissionais. A diferença entre os dois grupos na Rev2 foi similar à diferença encontrada na Rev1.

Como um todo, o grupo dos tradutores expertos produziu mais texto "desnecessário" do que o grupo dos semiprofissionais, tanto com verbalização como sem ela (média de 19,6 contra 17,1). Embora esse resultado tenha sido fortemente influenciado pelo comportamento de um participante em particular (7), é interessante observar que os tradutores expertos 
realizaram revisões substanciais a fim de melhorar as soluções para além da mera aceitabilidade.

\subsection{ANOVA do efeito da verbalização e direcionalidade na revisão (Rev2)}

Os dados de revisão também foram analisados utilizando-se a análise de variância $2 \times 2 \times 2$. Essa análise mostrou que a expertise teve um efeito não significativo, com uma quantidade pouco maior de revisão realizada pelos tradutores expertos (17,12 contra 19,55; $F(1,7)=0,210 ; p>0,05)$. Os principais efeitos da verbalização e da direcionalidade também não foram significativos. Os testes dos efeitos simples para a interação entre expertise e verbalização mostraram que os tradutores expertos produziram mais revisão do que os semiprofissionais, principalmente quando não verbalizaram durante a tradução $(21,78$ contra 17,84, com TAP; 17,33 contra 18,4, sem TAP; $F(1,7)=2,89 ; p>0,13)$, mas nenhum dos efeitos simples foi significativo.

Em suma:

- contrariando as expectativas e as hipóteses, nenhum efeito significativo foi encontrado entre direcionalidade e revisão, tanto considerando Rev1 como considerando Rev2 (ou mesmo Rev3);

- como se esperava, não foi encontrado nenhum efeito significativo global da verbalização na revisão. Entretanto, os valores de Rev2, para o grupo dos tradutores expertos, sugerem que a verbalização teve, sim, nesse grupo, um efeito sobre a revisão: todos os participantes (à exceção do 6) efetuaram consideravelmente mais revisão sem o TAP do que com ele, e a não significância estatística provavelmente pode ser atribuída ao pequeno tamanho da amostra;

- apesar de os tradutores expertos terem produzido textos, sem dúvida, com maior confiança do que os semiprofissionais, aparentemente fizeram uma quantidade de mudanças no texto igual ou mesmo maior do que os tradutores semiprofissionais.

\section{Efeitos sobre a segmentação}

Uma das questões mais intrigantes da psicolinguística diz respeito ao modo como o processamento da linguagem humana (compreensão e produção) acontece através do agrupamento do fluxo de informações, criando um ritmo cognitivo parecido com o ritmo sistólico-diastólico do coração. Um pressuposto básico por trás do método analítico adotado 
no presente estudo é que o processamento cognitivo da informação leva tempo (cf. BUTTERWORTH, 1980; SCHILPEROORD, 1996; DANKS et al., 1997). Se a tradução da L1 $\rightarrow$ L2 e a tradução com verbalização forem mais demoradas, tem-se que elas também requerem mais cognição e exigem maiores esforços da capacidade de processamento. Entretanto, o fato de que algumas condições desaceleram a execução da tarefa não significa, necessariamente, que a exigência sobre a capacidade de processamento produz diferentes segmentações ou "agrupamentos". Pode ser que segmentos individuais tenham permanecido da mesma forma, mas o processamento de cada segmento (sob certas condições) tenha sido mais lento, ou as pausas entre os segmentos tenham sido mais longas. Parece, contudo, que a realização do TAP de fato compeliu os participantes não apenas a meramente processar, de forma diferente, mais ou menos segmentos idênticos, mas também a processar diferentes segmentos.

A forma mais óbvia de identificar segmentos no desenho experimental aqui adotado foi dizer, de forma ad hoc e não linguística, que o segmento consiste em uma sequência de acionamentos de teclas que ocorre entre duas pausas com duração maior que certo valor de tempo predeterminado. A duração da pausa é uma base atrativa para a segmentação dos dados do Translog, pois a informação relevante é disponibilizada pelos dados registrados pelo programa. Não é claro, entretanto, se a duração (ou as durações) das pausas constitui(em) um bom critério. Nos dados, não houve valores com limites claros na distribuição das pausas (relacionados, por exemplo, a sentenças ou palavras); portanto, não foi estatisticamente claro que duração de pausa poderia ser utilizada na definição de um segmento.

Não se encontrou uma definição de segmento baseada na delimitação das pausas que pudesse ser correlacionada perfeitamente com os dados de produção textual e/ou verbalização do pensamento em voz alta. Há também a possibilidade de que a segmentação possa diferir participante para participante, sendo esse outro fator que a definição aqui adotada é incapaz de levar em consideração ${ }^{7}$.

Schilperoord (1996, p. 92-93) identificou, em um corpus oral, que as durações médias das pausas que coincidem com o limite da sentença e com o limite dos parágrafos ${ }^{8}$ são de respectivamente em torno de 2,6 s e 8,3 s. Ambas as médias resultaram de dados que mostravam "variâncias consideráveis". Goldman-Eisler (1972) também encontrou grande

\footnotetext{
${ }^{7}$ Há também o problema de muitas pausas serem indicativas de processamento tanto de novas informações quanto de informações já trabalhadas. Lorenzo (1999, p. 26) sugere um método prático para distinguir pausas de monitoramento de pausas de planejamento.

${ }^{8}$ Schilperoord (1996, p. 82) analisa seus dados orais em seis níveis hierárquicos de expressividade linguística: texto, parágrafos, frases, orações, sintagmas e palavras.
} 
variação na duração das pausas entre sentenças na fala espontânea, muitas das quais eram mais longas que 2,5 s. Butterworth (1980, p. 165) observou que os ciclos de pausas e enunciados geralmente duram entre $18 \mathrm{~s}$ e $30 \mathrm{~s}$; que o limite de cada ciclo coincide quase que invariavelmente com o limite da oração e geralmente contém de cinco a oito orações; e que esses ciclos se correlacionam com "ideias" (unidades semânticas) bem como com gestos e olhares em uma comunicação face a face.

A definição ad hoc de segmento adotada nesta parte do estudo considerou mecanicamente que qualquer quantidade de acionamentos de teclas entre duas pausas de $5 \mathrm{~s}$ (ou mais) constitui um segmento. As durações médias dos segmentos encontrados seguindo esse critério foram surpreendentemente uniformes para todos os participantes (entre $30 \mathrm{~s}$ e $35 \mathrm{~s}$ ), embora com uma variação considerável dependendo da tarefa. No entanto, o número de segmentos para cada tarefa diferiu consideravelmente; os efeitos principais foram, mais uma vez, a direcionalidade e a verbalização.

Outro problema foi decidir se os números de segmentos encontrados deveriam ser relacionados com as unidades do texto-fonte, os acionamentos de teclas (totais ou apenas aqueles referentes à produção textual) ou as unidades da versão final do texto-alvo. Calcular os números dos segmentos pelas unidades do texto-fonte favoreceria a perspectiva da compreensão, ao passo que calcular os segmentos pelos outros valores beneficiaria a perspectiva da produção. Entretanto, isso acabou por não ser um problema visto que os valores encontrados foram praticamente idênticos. Por essa razão, apenas os valores para o número de segmentos relativo às unidades do texto-fonte (100 caracteres incluindo-se espaços) são apresentados a seguir.

\subsection{Efeitos da direcionalidade e da verbalização}

O número de segmentos (pelo critério de $5 \mathrm{~s}$ ) no grupo dos semiprofissionais é mostrado na Tabela 11. O número médio de segmentos a cada 100 caracteres do texto-fonte variou entre 3,16 e 9,54. Todos os participantes apresentaram mais segmentos - a cada 100 caracteres do texto-fonte $(\mathrm{TF})$ - durante a tradução do texto 1 , que foi o mais curto. $\mathrm{O}$ alto número de segmentos para esse texto não pode ser atribuído à curta extensão do texto-fonte, uma vez que o segundo maior número de segmentos (por caracteres do TF) ocorreu no texto mais logo (texto 4).

Na tradução da L1 para L2, os participantes tiveram uma média de 7,09 segmentos a cada 100 caracteres do TF, 21,7\% mais do que na tradução da L2 para L1 $(5,55)$. Na tradução 
com verbalização, os participantes tiveram uma média de 7,49 segmentos por unidade do TF, $31,2 \%$ mais do que quando não foi realizada a verbalização durante a tradução $(5,15)$.

Tabela 11 - Valores da segmentação no grupo dos semiprofissionais

\begin{tabular}{|c|c|c|c|c|c|c|c|c|c|}
\hline Part. & Texto & $\begin{array}{l}\text { Condição } \\
\text { (TAP) }\end{array}$ & Direção & $\begin{array}{l}\text { № de } \\
\text { segm. }\end{array}$ & $\begin{array}{l}\text { № de segm./100 } \\
\text { caracteres do TF }\end{array}$ & $\begin{array}{c}\text { Média por } \\
\text { texto }\end{array}$ & $\begin{array}{c}\text { Por } \\
\text { direção }\end{array}$ & $\begin{array}{l}\text { Por uso } \\
\text { do TAP }\end{array}$ & Por part. \\
\hline 1 & 1 & Com TAP & $\mathrm{L} 1 \rightarrow \mathrm{L} 2$ & 33 & 8,99 & & & & \\
\hline 2 & 1 & Com TAP & $\mathrm{L} 1 \rightarrow \mathrm{L} 2$ & 35 & 9,54 & & & & \\
\hline 3 & 1 & Com TAP & $\mathrm{L} 1 \rightarrow \mathrm{L} 2$ & 29 & 7,90 & Txtl & & & S1 \\
\hline 4 & 1 & Com TAP & $\mathrm{L} 1 \rightarrow \mathrm{L} 2$ & 31 & 8,45 & 8,72 & & & 6,80 \\
\hline 1 & 4 & Com TAP & $\mathrm{L} 2 \rightarrow \mathrm{L} 1$ & 68 & 6,79 & & & & \\
\hline 2 & 4 & Com TAP & $\mathrm{L} 2 \rightarrow \mathrm{L} 1$ & 75 & 7,49 & & & & \\
\hline 3 & 4 & Com TAP & $\mathrm{L} 2 \rightarrow \mathrm{L} 1$ & 38 & 3,80 & Txt4 & $\mathrm{L} 1 \rightarrow \mathrm{L} 2$ & Com TAP & S2 \\
\hline 4 & 4 & Com TAP & $\mathrm{L} 2 \rightarrow \mathrm{L} 1$ & 70 & 6,99 & 6,27 & 7,09 & 7,49 & 6,05 \\
\hline 1 & 2 & Sem TAP & $\mathrm{L} 1 \rightarrow \mathrm{L} 2$ & 30 & 5,75 & & & & \\
\hline 2 & 2 & Sem TAP & $\mathrm{L} 1 \rightarrow \mathrm{L} 2$ & 21 & 4,02 & & & & \\
\hline 3 & 2 & Sem TAP & $\mathrm{L} 1 \rightarrow \mathrm{L} 2$ & 20 & 3,83 & Txt2 & & & S3 \\
\hline 4 & 2 & Sem TAP & $\mathrm{L} 1 \rightarrow \mathrm{L} 2$ & 43 & 8,24 & 5,46 & & & 4,87 \\
\hline 1 & 3 & Sem TAP & $\mathrm{L} 2 \rightarrow \mathrm{L} 1$ & 43 & 5,66 & & & & \\
\hline 2 & 3 & Sem TAP & $\mathrm{L} 2 \rightarrow \mathrm{L} 1$ & 24 & 3,16 & & & & \\
\hline 3 & 3 & Sem TAP & $\mathrm{L} 2 \rightarrow \mathrm{L} 1$ & 30 & 3,95 & Txt3 & $\mathrm{L} 2 \rightarrow \mathrm{L} 1$ & Sem TAP & S4 \\
\hline \multirow[t]{2}{*}{4} & 3 & Sem TAP & $\mathrm{L} 2 \rightarrow \mathrm{L} 1$ & 50 & 6,58 & 4,84 & 5,55 & 5,15 & 7,56 \\
\hline & & & MÉDIA & 40 & 6,32 & & & & \\
\hline
\end{tabular}

Nota: Part.=participante; segm.=segmento; TF=texto-fonte; TAP=protocolo de verbalização do pensamento em voz alta.

Os valores referentes ao grupo dos tradutores expertos se encontram na Tabela 12. O número médio de segmentos a cada 100 caracteres do texto-fonte variou entre 2,18 e 8,43. Todos os tradutores expertos (exceto o 9) apresentaram mais segmentos na tradução do texto 2 quando traduziram os mesmos textos-fonte que os semiprofissionais, mas em condições opostas de realização do TAP. O texto 3 , que teve os menores números de segmentos por unidade do TF no grupo dos semiprofissionais, apresentou agora o segundo maior número.

Na tradução da L1 para a L2, os tradutores expertos tiveram uma média de 5,74 segmentos a cada 100 caracteres do TF, $16,7 \%$ mais do que quando traduziram da L2 para a L1 (4,78). Traduzindo com verbalização, os participantes tiveram uma média de 5,90 segmentos por unidade do TF, $21,7 \%$ mais do que quando não foi realizada a verbalização durante a tradução $(4,62)$. 
Os participantes foram afetados de formas diferentes pela realização do TAP. Todos apresentaram mais segmentos por unidade do TF quando traduziram com verbalização. $\mathrm{O}$ participante 6 teve quase $50 \%$ menos segmentos por unidade do TF quando traduziu sem verbalização, enquanto o participante 9 teve apenas $4 \%$ menos segmentos.

Desse modo, a sétima e última hipótese foi refutada pelos dados. A verbalização afetou de forma clara a segmentação: forçou os tradutores, sejam eles rápidos ou lentos, expertos ou não, a dividir a produção do texto de chegada em segmentos menores.

Tabela 12 - Valores da segmentação no grupo dos tradutores expertos

\begin{tabular}{|c|c|c|c|c|c|c|c|c|c|}
\hline Part. & Texto & $\begin{array}{c}\text { Condição } \\
\text { (TAP) }\end{array}$ & Direção & $\begin{array}{l}\text { № de } \\
\text { segm. }\end{array}$ & $\begin{array}{c}\text { № de } \\
\text { segm./100 } \\
\text { caracteres do TF }\end{array}$ & $\begin{array}{c}\text { Média por } \\
\text { texto }\end{array}$ & $\begin{array}{c}\text { Por } \\
\text { direção }\end{array}$ & $\begin{array}{c}\text { Por uso do } \\
\text { TAP }\end{array}$ & Por part. \\
\hline 5 & 2 & Com TAP & $\mathrm{L} 1 \rightarrow \mathrm{L} 2$ & 35 & 6,70 & & & & \\
\hline 6 & 2 & Com TAP & $\mathrm{L} 1 \rightarrow \mathrm{L} 2$ & 32 & 6,13 & & & & \\
\hline 7 & 2 & Com TAP & $\mathrm{L} 1 \rightarrow \mathrm{L} 2$ & 44 & 8,43 & & & & S5 \\
\hline 8 & 2 & Com TAP & $\mathrm{L} 1 \rightarrow \mathrm{L} 2$ & 29 & 5,56 & Txt2 & & & 5,23 \\
\hline 9 & 2 & Com TAP & $\mathrm{L} 1 \rightarrow \mathrm{L} 2$ & 30 & 5,75 & 6,51 & & & \\
\hline 5 & 3 & Com TAP & $\mathrm{L} 2 \rightarrow \mathrm{L} 1$ & 35 & 4,61 & & & & S6 \\
\hline 6 & 3 & Com TAP & $\mathrm{L} 2 \rightarrow \mathrm{L} 1$ & 35 & 4,61 & & & & 4,04 \\
\hline 7 & 3 & Com TAP & $\mathrm{L} 2 \rightarrow \mathrm{L} 1$ & 48 & 6,32 & & & & \\
\hline 8 & 3 & Com TAP & $\mathrm{L} 2 \rightarrow \mathrm{L} 1$ & 28 & 3,68 & Txt3 & $\mathrm{L} 1 \rightarrow \mathrm{L} 2$ & Com TAP & S7 \\
\hline 9 & 3 & Com TAP & $\mathrm{L} 2 \rightarrow \mathrm{L} 1$ & 55 & 7,24 & 5,29 & 5,74 & 5,90 & 6,83 \\
\hline 5 & 1 & Sem TAP & $\mathrm{L} 1 \rightarrow \mathrm{L} 2$ & 22 & 5,99 & & & & \\
\hline 6 & 1 & Sem TAP & $\mathrm{L} 1 \rightarrow \mathrm{L} 2$ & 10 & 2,72 & & & & S8 \\
\hline 7 & 1 & Sem TAP & $\mathrm{L} 1 \rightarrow \mathrm{L} 2$ & 26 & 7,08 & & & & 3,83 \\
\hline 8 & 1 & Sem TAP & $\mathrm{L} 1 \rightarrow \mathrm{L} 2$ & 8 & 2,18 & Txtl & & & \\
\hline 9 & 1 & Sem TAP & $\mathrm{L} 1 \rightarrow \mathrm{L} 2$ & 25 & 6,81 & 4,96 & & & S9 \\
\hline 5 & 4 & Sem TAP & $\mathrm{L} 2 \rightarrow \mathrm{L} 1$ & 36 & 3,60 & & & & 6,37 \\
\hline 6 & 4 & Sem TAP & $\mathrm{L} 2 \rightarrow \mathrm{L} 1$ & 27 & 2,70 & & & & \\
\hline 7 & 4 & Sem TAP & $\mathrm{L} 2 \rightarrow \mathrm{L} 1$ & 55 & 5,49 & & & & \\
\hline 8 & 4 & Sem TAP & $\mathrm{L} 2 \rightarrow \mathrm{L} 1$ & 39 & 3,90 & Txt4 & $\mathrm{L} 2 \rightarrow \mathrm{L} 1$ & Sem TAP & \\
\hline \multirow[t]{2}{*}{9} & 4 & Sem TAP & $\mathrm{L} 2 \rightarrow \mathrm{L} 1$ & 57 & 5,69 & 4,28 & 4,78 & 4,62 & \\
\hline & & & MÉDIA & 33,8 & 5,26 & & & & \\
\hline
\end{tabular}

Nota: Part.=participante; TAP =protocolo de verbalização do pensamento em voz alta.

Ao contrário do que havia sido previsto de acordo com a teoria de Ericsson e Simon (1993), houve um efeito claro da realização do TAP sobre a segmentação. Não aconteceu de os segmentos com o mesmo tamanho levarem mais tempo para serem processados com a 
verbalização. Os segmentos processados em movimento cognitivo sistólico-diastólico foram muito mais curtos e diferentes.

\subsection{ANOVA dos dados de segmentação}

Os dados da segmentação também foram analisados utilizando-se a análise de variância $2 \times 2 \times 2$. Essa análise mostrou um efeito não significativo da expertise, tendo, o grupo dos semiprofissionais, o maior número de segmentações $(6,32$ contra 5,26; $F(1,7)=1,57$; $p>0,05)$. Os outros dois efeitos principais foram significativos: houve mais segmentações com a verbalização do que sem ela $(6,70$ contra 4,$88 ; \mathrm{F}(1,7)=14,401 ; \mathrm{p}=0,007)$; e houve mais segmentos na direção $\mathrm{L} 1 \rightarrow \mathrm{L} 2$ do que na direção $\mathrm{L} 2 \rightarrow \mathrm{L} 1(6,41$ contra 5,$17 ; \mathrm{p}=0,003)$.

A interação entre a realização do TAP e a direcionalidade não foi significativa $(p=0,14)$. Entretanto, testes do efeito simples mostraram que a condição de uso do TAP foi significativa na direção $\mathrm{L} 1 \rightarrow \mathrm{L} 2(7,62$ contra 5,$21 ; \mathrm{F}(1,7)=12,27 ; \mathrm{p}=0,01)$ e na direção $\mathrm{L} 2 \rightarrow \mathrm{L} 1 \quad(5,78$ contra 4,56; $\mathrm{F}(1,7)=6,34 ; \mathrm{p}=0,04)$, bem como que a direcionalidade foi significativa na condição de verbalização $(7,62$ contra 5,$78 ; F(1,7)=15,74 ; p=0,005)$.

Em suma:

- como previsto, a segmentação variou de acordo com a direcionalidade. Os participantes segmentaram o texto de chegada mais frequentemente (a cada 100 caracteres do texto-fonte) quando traduziram da L1 para a L2 do que da L2 para a L1;

- ao contrário do que havia sido previsto, verificou-se que a verbalização do pensamento em voz alta, em ambos os grupos, aumentou significativamente o número de segmentos na produção textual.

\section{Conclusão}

Os resultados do presente estudo identificaram e quantificaram efeitos mais significativos da verbalização nas tarefas de tradução do que aqueles previstos por Ericsson e Simon (1993). Presume-se que o conhecimento ativado durante a tradução esteja armazenado verbalmente na memória. De acordo com Ericsson e Simon (1993), a verbalização não afeta a forma e a natureza do processamento de informação. O presente estudo mostra que a influência da verbalização no processamento durante a tradução é bastante considerável. Embora esses resultados nos forcem a rever suposições sobre a técnica de verbalização do 
pensamento em voz alta para os propósitos de pesquisa em tradução, eles não invalidam, de modo algum, o método. Na verdade, o método mais óbvio para tentar responder a muitas das questões levantadas pelos experimentos aqui relatados - e deixadas sem resposta na análise quantitativa dos dados do Translog - seria tentar aventar hipóteses baseadas tanto nos dados quantitativos registrados no computador como nos dados qualitativos dos TAP.

\section{Agradecimentos}

Gostaria de agradecer a Robert J. Jarvella, Barbara Dragsted, Inger Mees e mais dois revisores anônimos por seus comentários prestativos sobre o artigo.

\section{Referências}

ALVES, F. A triangulação como opção metodológica em pesquisas empírico-experimentais em tradução. In: PAGANO, A. (Ed.), Metodologias de pesquisa em tradução. Belo Horizonte: FALE-UFMG, 2001, p. 69-92.

BADDELEY, A. D.; GATHERCOLE, S. E.; PAPAGNO, C. The phonological loop as a language learning device. Psychological Review, v. 105, n. 1, p. 158-173, 1998.

BUTTERWORTH, B. Evidence from pauses in speech. In: BUTTERWORTH, B. (Ed.). Language production: Londres: Academic Press, 1980. v. 1. p. 155-176.

DANKS, J. S.; SHREVE, G. N.; FOUNTAIN, S. B.; MCBEATH, M. K. (Ed.). Cognitive processes in translation and interpreting. Londres: Sage, 1997.

ERICSSON, K. A.; SIMON, H. A. Protocol analysis: verbal reports as data. 2. ed. Cambridge: MIT Press, 1993[1984].

GOLDMAN-EISLER, F. Pauses, clauses, sentences. Language and Speech, v. 15, p.103-113, 1972.

HANSEN, G. (Ed.). Probing the process in translation: methods and results. Copenhagen: Samfundslitteratur, 1999.

HANSEN, G. (Ed.). Empirical translation studies: process and product. Copenhagen: Samfundslitteratur, 2002.

JAKOBSEN, A. L. Logging time delay in translation. In: HANSEN, G. (Ed.). LSP texts and the process of translation. Copenhagen: Copenhagen Business School, 1998. p. 73-101.

JAKOBSEN, A. L.; SCHOU, L. Translog documentation. In: HANSEN, G. (Ed.). Probing the process in translation: methods and results. Copenhagen: Samfundslitteratur, 1999. p. 136. Appendix 1. 
JAKOBSEN, A. L. Logging target text production with Translog. In: HANSEN, G (Ed.), Probing the process in translation: methods and results. Copenhagen: Samfundslitteratur, 1999. p. 9-20.

JAKOBSEN, A. L. Translation drafting by professional translators and by translation students. In: HANSEN, G. (Ed.). Empirical translation studies: process and product Copenhagen: Samfundslitteratur, 2002. p. 191-204.

JÄÄSKELÄINEN, R. Tapping the process: an explorative study of the cognitive and affective factors involved in translating. Joensuu: Joensuun yliopisto, 1999.

KRINGS, H. P. Repairing texts: empirical investigations of machine translation post-editing processes. Tradução de Geoffrey S. Koby, George M. Shreve, Katja Mischerikow e Sarah Litzer. Kent, Ohio: Kent State University Press, 2001.

LORENZO, M. P. Apuntes para una discusión sobre métodos de estudio del proceso de traducción. In: HANSEN, G. (Ed.), Probing the process in translation: methods and results. Copenhagen: Samfundslitteratur, 1999. p. 21-42.

MOSSOP, B. Revising and editing for translators. Manchester: St. Jerome, 2001.

SCHILPEROORD, J. It's about time: temporal aspects of cognitive processes in text production. Amsterdã: Rodopi, 1996.

TIRKKONEN-CONDIT, S.; JÄÄSKELÄINEN, R. (Ed.). Tapping and mapping the processes of translation and interpreting: outlooks on empirical research. Amsterdã: John Benjamins, 2000. 